\title{
LOCALIZATION OF CHOLINESTERASE AT SITES OF HIGH ACETYLCHOLINE RECEPTOR DENSITY ON EMBRYONIC AMPHIBIAN MUSCLE CELLS CULTURED WITHOUT NERVE ${ }^{1}$
}

\author{
F. MOODY-CORBETT AND M. W. COHEN
}

Department of Physiology, McGill University, Montreal, Quebec, Canada H3G 1 Y6

\begin{abstract}
Myotomal muscle cells, derived from Xenopus embryos and grown in culture without nerve, develop discrete sites of cholinesterase (ChE) activity on their surface. The spatial relationship of these ChE patches to surface patches of acetylcholine receptors (AChRs) has been examined in the present study by a combination of $\mathrm{ChE}$ histochemistry and fluorescent staining of the receptors.

ChE patches and AChR patches developed as early as the 1st day in culture and exhibited a high incidence of spatial overlap. The frequency of overlap varied with the age of the culture and ranged from 50 to $98 \%$ for patches on the lower cell surface (facing the floor of the culture dish) and from 28 to $79 \%$ for patches on the upper cell surface. The high incidence of overlap cannot be explained on the basis of a random distribution of patches since both types of patch occupied less than $3 \%$ of the cell surface. $\mathrm{ChE}$ and AChR patches also developed when cultures were grown in a serum-free medium as well as when cultures were prepared from young embryos in which muscle innervation had not yet begun. At some patches, the surface membrane was invaginated and at these invaginations, there was also a high incidence of overlap between the $\mathrm{ChE}$ and $\mathrm{AChR}$ stains.

It is concluded that the mechanisms involved in the localization of AChRs and ChE on the surface of Xenopus myotomal muscle cells tend to be closely linked and operate even in the absence of innervation, previous contact by nerve, or electrical and contractile activity. Considered together with previous ultrastructural observations, the present findings suggest that these cells develop elaborate postsynaptic-like specializations even in the absence of neural factors.
\end{abstract}

In skeletal muscle, acetylcholine receptors (AChRs) and cholinesterase (ChE) are both present in high density at the neuromuscular junction and become localized there very early during the development of the synapse (Diamond and Miledi, 1962; Bennett and Pettigrew, 1974; Bevan and Steinbach, 1977; Kullberg et al., 1977, 1980; Chow, 1980). That nerve can induce the localization of both of these molecules at sites of innervation has been revealed in cultures of embryonic nerve and muscle cells (Anderson and Cohen, 1977; Anderson et al., 1977; Frank and Fischbach, 1979; Rubin et al., 1979) and in studies on the reinnervation of adult muscle in vivo (Aitken, 1950; Miledi, 1962; Fex et al., 1966; Lomo and Slater, 1980 ). Recent studies have also indicated that some of the factors which regulate the localization of $\mathrm{ChE}$ may be different from those which regulate the localization of

${ }^{1}$ This work was supported by the Medical Research Council of Canada. Personal support to F. M. -C. from the Faculty of Medicine, McGill University and to M. W. C. from Le Conseil de la Recherche en Santé du Québec is also gratefully acknowledged. We thank Dr. R. I. Birks for the use of his microscope facilities and for continued interest in this work. Mr. C. Cantin provided expert technical assistance.
AChRs. For instance, muscle contractile activity is important for the accumulation of $\mathrm{ChE}$ at sites of innervation in rat and chick muscle but not for the accumulation of AChRs (Koenig and Vigny, 1979; Rubin et al., 1979, 1980; Weinberg and Hall, 1979; Lomo and Slater, 1980). In addition, embryonic muscle cells from rat and chick develop surface patches of high AChR density even when they are cultured in the absence of nerve (Vogel et al., 1972; Fischbach and Cohen, 1973; Axelrod et al., 1976), but surface patches of cholinesterase have rarely been observed in such cultures (Axelrod et al., 1978; Koenig and Vigny, 1978; Rubin et al., 1979).

In contrast to the above observations on rat and chick embryonic muscle, we have recently found that discrete patches of ChE do develop on the surface of embryonic Xenopus muscle cells cultured without nerve and in the absence of muscle activity (Weldon et al., 1981). In the present study, we have examined the development of these ChE patches in more detail and have compared their distribution to that of the $\mathrm{AChR}$ patches which also develop in these cultures (Anderson et al., 1977). The results indicate that there is a high incidence of spatial overlap between the $\mathrm{ChE}$ and $\mathrm{AChR}$ patches and that 
the development of both types of patch does not require previous contact with nerve. Apparently the mechanisms which regulate cholinesterase localization and receptor localization are linked more intimately in embryonic Xenopus muscle cells than in embryonic rat or chick muscle cells and can operate even in the absence of neural factors.

A brief account of this work has been reported previously (Moody-Corbett and Cohen, 1979).

\section{Materials and Methods}

The preparation of these muscle cultures has been described previously (Anderson et al., 1977; Weldon et al., 1981). All dissections were done under sterile conditions. Briefly, the myotomal muscle of 1-day-old (stage 22 to 24, Nieuwkoop and Faber, 1967) Xenopus laevis embryos was separated from the surrounding tissues with the aid of collagenase $(1 \mathrm{mg} / \mathrm{ml})$. The myotomes were further dissociated in a calcium-magnesium-free solution of trypsin $(50 \mathrm{mg} / \mathrm{ml})$ and EDTA (ethylenediaminetetraacetate, $20 \mathrm{mg} / \mathrm{ml}$ ) for approximately $1 \mathrm{hr}$. Muscle cells were then transferred to culture chambers containing plating medium (67\% L-15, 5\% dialyzed horse serum) and 1 day later, the plating medium was replaced with a maintenance medium $(67 \% \mathrm{~L}-15,0.2 \mu \mathrm{g} / \mathrm{ml}$ of Holmes' $\alpha$-1-protein). All components of the culture medium were obtained from Grand Island Biological Co. of Canada Ltd. (Burlington, Ontario). Culture chambers were constructed as described by Anderson et al. (1977), their floor consisting of a collagen-coated glass coverslip. The cultures were kept at room temperature $\left(22\right.$ to $\left.24^{\circ} \mathrm{C}\right)$.

As indicated under "Results," the culture procedure was modified for some experiments in one of the following ways. (1) Some cultures were plated and maintained in $67 \%$ L-15 by itself, without any serum supplements. In one case, the culture chamber consisted of an untreated 35-mm Falcon dish. (2) Some cultures were prepared from stage 14 to 16 embryos. Distinct myotomes have not yet formed at these early stages, but the developing myotomal cells are already segregated into a band of tissue on either side of the notochord (Nieuwkoop and Faber, 1967; Hamilton, 1969). The stage 14 to 16 embryos were treated in the same way as stage 22 to 24 embryos, and the collagenase treatment (see above) proved to be effective in allowing the bands of developing myotomal cells to be separated from all surrounding tissue, including the overlying neural tissue.

To visualize sites of high $\mathrm{AChR}$ density and $\mathrm{ChE}$ activity, the cultures were stained with $\alpha$-bungarotoxin conjugated with tetramethylrhodamine (Anderson and Cohen, 1974; Anderson et al., 1977), fixed for 20 to 60 min, rinsed with frog Ringer's solution, and then stained for 10 to $20 \mathrm{~min}$ at room temperature by the method of Karnovsky (1964). The staining solution contained (in millimolar concentrations): acetylthiocholine iodide, 1.8; acetate buffer, 65 , at $\mathrm{pH} 5.0$; sodium citrate, 15; copper sulfate, 3 ; potassium ferricyanide, 0.5. A fixative composed of glutaraldehyde $(0.15 \%)$ and formaldehyde $(2 \%)$ in L-15 (67\%) allowed both fluorescence and reaction product to be viewed on the same cells. When the initial fixation times were short, the cultures were post-fixed overnight at $4^{\circ} \mathrm{C}$ with $10 \%$ formaldehyde in $0.1 \mathrm{M}$ HEPES buffer (4-(2-hydroxyethyl)-1-piperazine-ethanesulfonic acid), $\mathrm{pH}$ 7.4. The fixed cultures were then rinsed, cleared in glycerol, and examined with phase contrast and fluorescence optics at magnifications of $\times 500$ to 800 .

In some experiments, the anticholinesterase neostigmine was tested to determine its effectiveness in inhibiting $\mathrm{ChE}$ activity. After receptor staining and fixation, sister cultures were exposed to different concentrations of the drug (neostigmine bromide or neostigmine methylsulfate; Sigma Chemical Co.), first for 25 to $35 \mathrm{~min}$ in Ringer's solution and then for the duration $(10 \mathrm{~min})$ of the period in Karnovsky's solution.

The relationship of $\mathrm{AChR}$ and $\mathrm{ChE}$ patches was examined from the 1 st to the 7 th day in culture. Unless otherwise indicated, 25 to 50 consecutive cells per culture were viewed and the number of patches, overlap, and precision of overlap were documented. Poorly fixed cells which exhibited blebs or which had partially detached and rounded up because of contraction during the fixation were not included. Such cases constituted only a small percentage of all of the cells in the cultures. In order to estimate the proportion of the lower cell surface occupied by AChR patches and by ChE patches, the cells were photographed, cut into their respective parts, and weighed. A calibrated, fine-focusing dial on the microscope permitted measurement of the depth of invaginations.

\section{Results}

Cholinesterase activity at sites of high receptor density. Discrete sites of ChE stain and of AChR stain were seen on virtually all ( $98 \%)$ of the cultured muscle cells. The ChE patches were similar in size to the AChR patches and likewise occurred on the lower cell surface facing the floor of the culture dish (Fig. 1) as well as on the upper cell surface which is not apposed to any solid substrate (Fig. 2). Furthermore, many of the ChE patches and $A C h R$ patches overlapped completely or nearly completely. Examples of AChR patches without any overlapping ChE stain (Fig. $2 B$ ) and of ChE patches without any apparent overlapping AChR stain (Figs. $1 C$ and $2 B$ ) were also observed.

In addition to the discrete $\mathrm{ChE}$ patches, less intense and more diffusely distributed $\mathrm{ChE}$ reaction product was occasionally observed. In some cases, this diffuse distribution was continuous with the intense $\mathrm{ChE}$ patches and may have arisen from them by diffusion of the reaction product. In other cases, the diffuse distribution was not continuous with the intense $\mathrm{ChE}$ patches, suggesting that these cells had regions with a low level of $\mathrm{ChE}$ activity in addition to patches of higher activity. This would be analogous to previous findings on the distribution of AChRs which have indicated not only discrete sites of high density but also a widespread lower density that is not readily resolved by fluorescent staining of $\mathrm{AChRs}$ (Anderson et al., 1977). Because of the infrequency of the more diffuse, low density distribution of $\mathrm{ChE}$ reaction product and the difficulty of resolving it, the rest of the data presented here concern only the discrete intense ChE patches.

Discrete patches of ChE reaction product presumably reflect discrete sites of high $\mathrm{ChE}$ activity. An alternative 

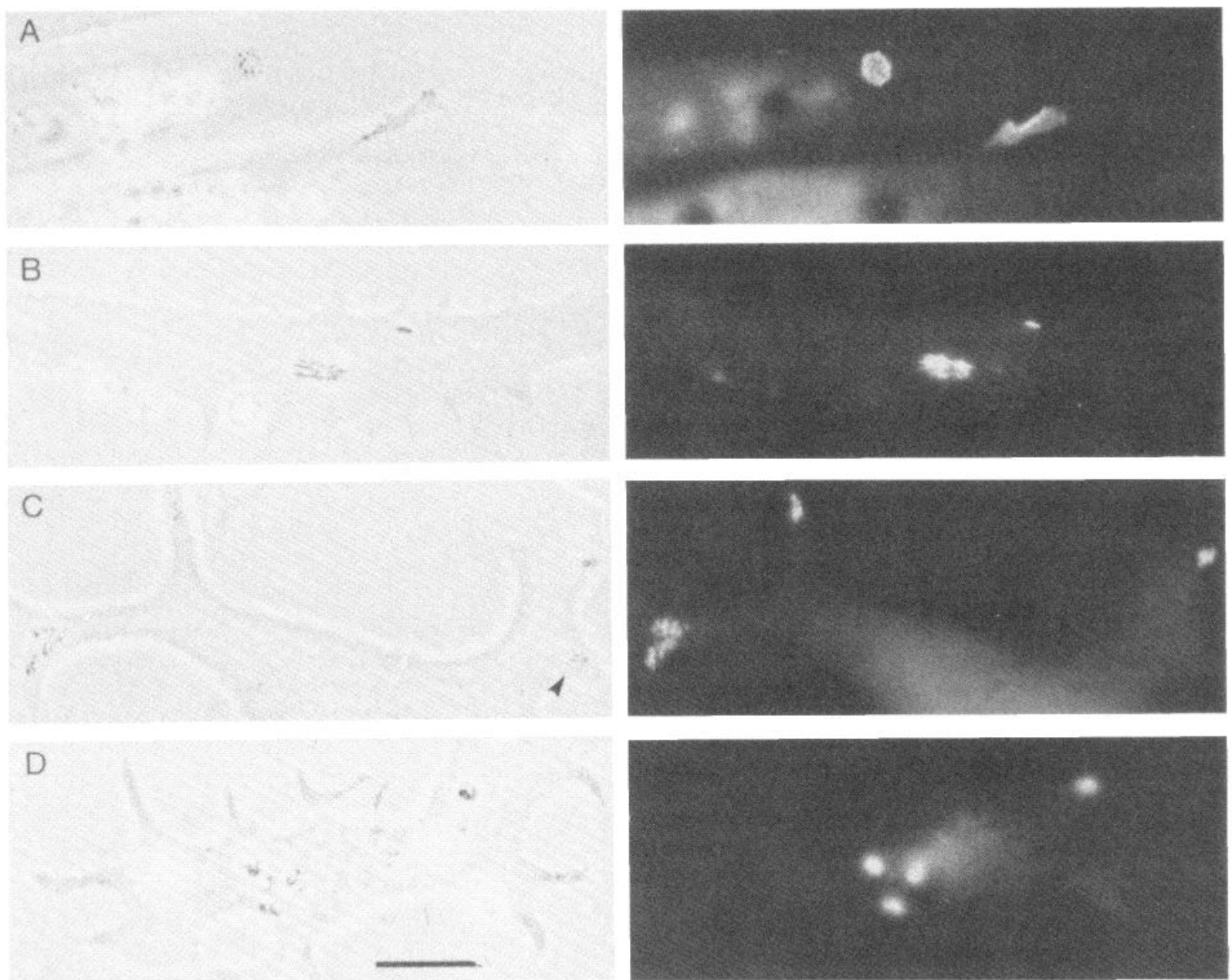

Figure 1. ChE patches (left) and AChR patches (right) on the lower surface of cultured muscle cells. A, Example of overlap of both types of patch in a 1-day culture. $B$, Example of overlap of both types of patch in a 5-day culture made from stage 14 to 16 embryos. $C$, Example in which all but one (arrowhead) of the ChE patches overlap with AChR patches, from a 6-day culture. $D$, Example of overlap of both types of patch in a 4-day culture grown on an untreated Falcon dish in culture medium which contained no serum supplements. Scale bar is $20 \mu \mathrm{m}$ and applies to the entire figure.

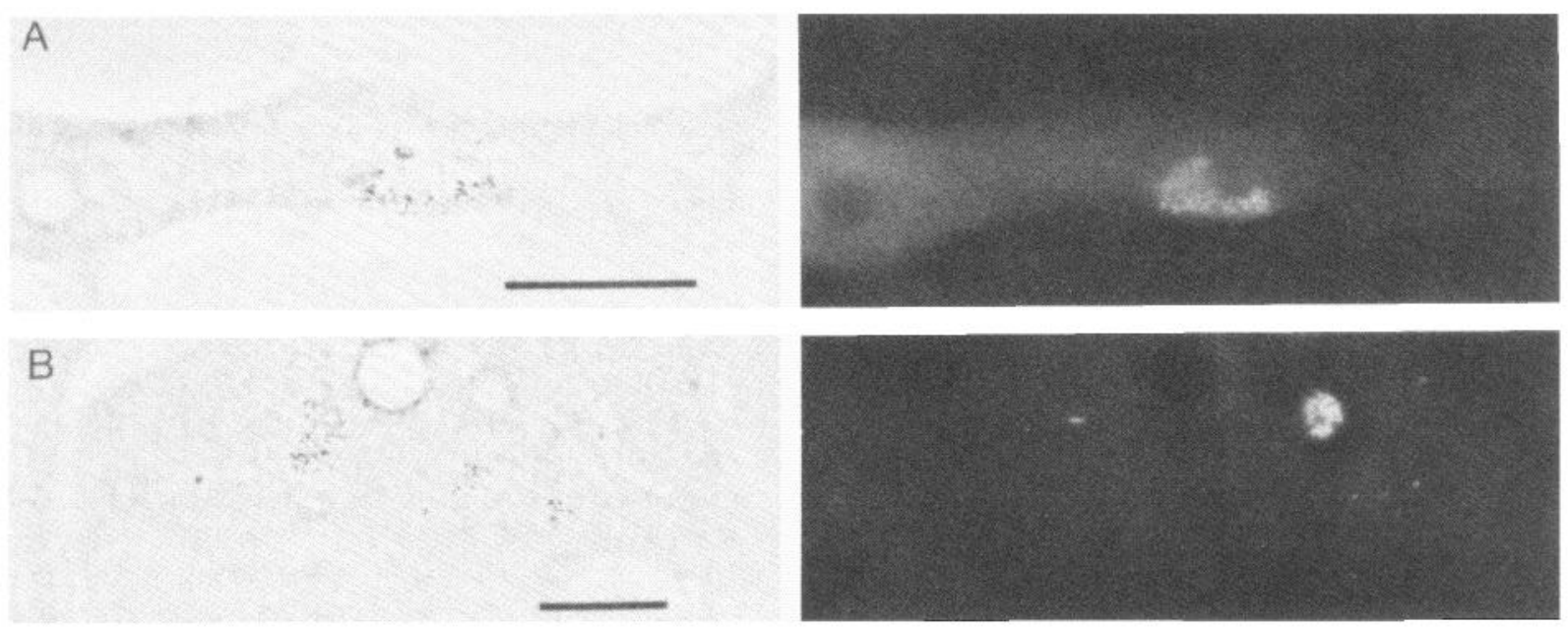

Figure 2. ChE patches (left) and AChR patches (right) on the upper surface of cultured muscle cells. Examples of overlap $(A)$ and lack of overlap $(B)$ of patches in 4-day cultures. Scale bars are $20 \mu \mathrm{m}$. 
possibility is that the enzyme is distributed uniformly over the entire cell, but the histochemical reaction product gets bound or trapped only at certain sites. This latter possibility was tested by extending the time of the histochemical reaction to $45 \mathrm{~min}$ and examining the distribution of reaction product on the floor of the culture dish in the vicinity of the muscle cells. As shown in Figure 3, there was little reaction product on the culture dish except immediately adjacent to sites where the edge of the muscle cell had a discrete ChE patch. Such results indicate that the enzyme is not distributed uniformly on the muscle cells and that the discrete patches of reaction product on the muscle cells are indeed sites of high $\mathrm{ChE}$ activity.

The frequency of overlap between AChR patches and ChE patches was assessed by examining all of the patches on individual cells chosen at random (see "Materials and Methods"). The results for patches on the lower cell surface are summarized in Figure 4. After 1 day in culture, the cells had more AChR patches than ChE patches. Sixty percent of the AChR patches (solid bar) were sites of $\mathrm{ChE}$ activity and $80 \%$ of the ChE patches (hatched bar) were sites of high AChR density. In older cultures (2 to 7 days), the ChE patches outnumbered the AChR patches. Nearly all (88 to $98 \%$ ) AChR patches were sites of $\mathrm{ChE}$ activity and 58 to $73 \%$ of the $\mathrm{ChE}$ patches were sites of AChR localization.

The results for patches on the upper surface of the same cells are summarized in Figure 5. In 2- and 4-dayold cultures, AChR patches outnumbered $\mathrm{ChE}$ patches. Over $74 \%$ of the ChE patches (hatched bars) were sites of high AChR density, whereas 43 and $64 \%$ of the AChR patches (solid bars) were sites of ChE activity. In 5- to 7-day cultures, the $\mathrm{ChE}$ patches outnumbered the AChR patches and the incidence of overlap tended to decrease with age, from 76 to $47 \%$ for the AChR patches (solid bars) and from 34 to $28 \%$ for the ChE patches (hatched bars). In 1-day cultures, patches of either type were rarely observed on the upper cell surface.

Following ChE histochemistry, the fluorescence at some AChR patches appeared less intense and the muscle cells exhibited increased autofluorescence, thereby raising the possibility that the absence of any obvious AChR stain at some of the ChE patches was due to these experimental limitations rather than to an absence of a high AChR density. In order to evaluate this possibility, $59 \mathrm{AChR}$ patches were first examined on the lower surface of identified living cells and then again after ChE histochemistry. In every case, the AChR patches were less obvious after the histochemistry and in two of these cases, the AChR patches were no longer apparent. Furthermore, the histochemistry revealed 23 additional $\mathrm{ChE}$ patches which clearly were not located at the same sites as the AChR patches. Two conclusions may be drawn from this experiment: (1) Localization of $\mathrm{ChE}$ can occur at sites where there is no obvious $\mathrm{AChR}$ accumulation
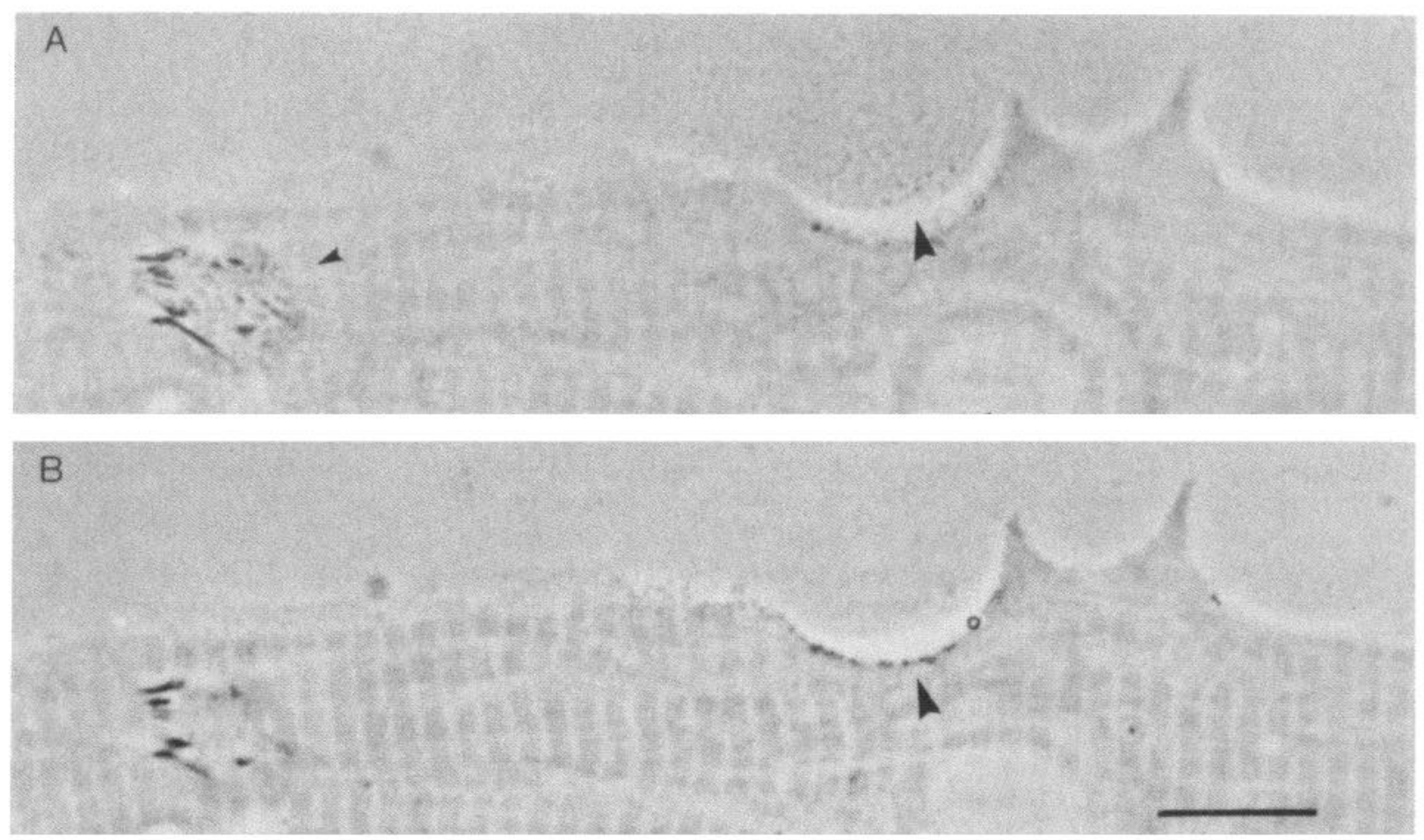

Figure 3. Distribution of ChE reaction product on the floor of the culture dish beside a muscle cell. The same field is viewed at two different planes of focus. A scattering of fine grains of reaction product is visible on the culture dish (large arrowhead in $A$ ) but only in the vicinity where the edge of the muscle cell has a ChE patch (arrowhead in $B$ ). Note also the ChE patch on the lower surface of the cell (small arrowhead in $A$ ) and its stained invaginations. For this experiment, the histochemical reaction was continued for $45 \mathrm{~min}$ rather than 10 to $20 \mathrm{~min}$. Scale bar is $10 \mu \mathrm{m}$. 


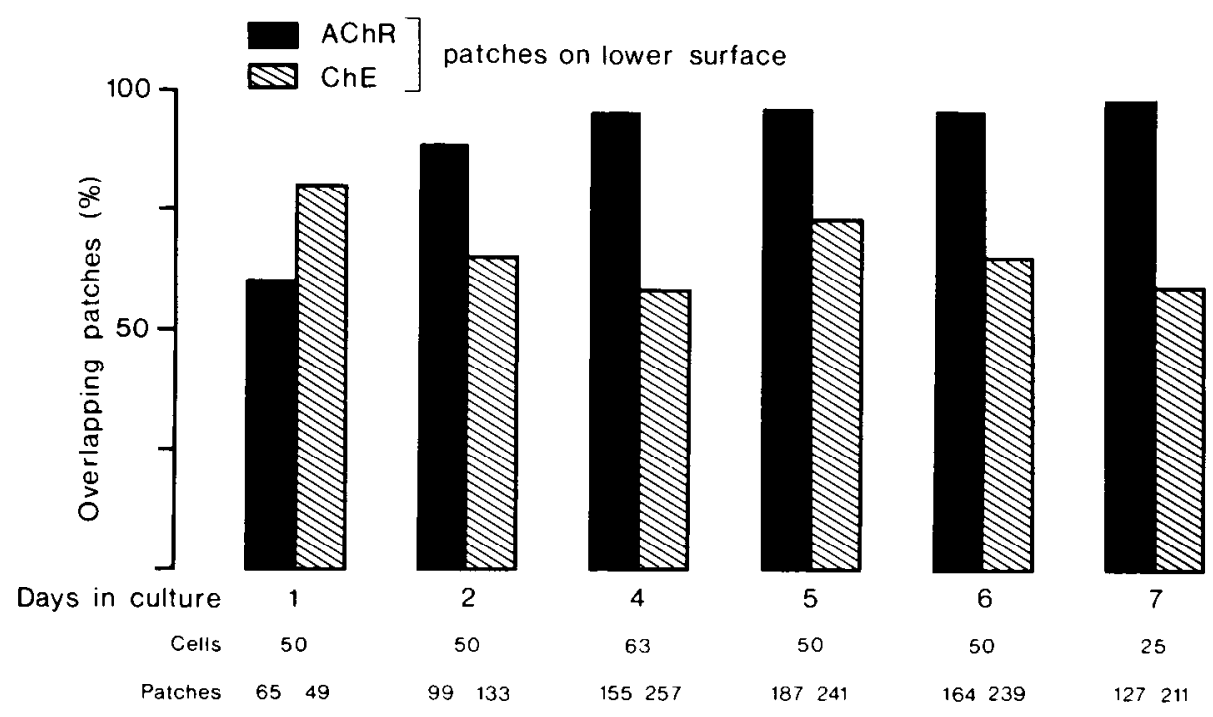

Figure 4. The percentage of $\mathrm{AChR}$ patches with $\mathrm{ChE}$ reaction product (solid bars) and the percentage of $\mathrm{ChE}$ patches with $\mathrm{AChR}$ stain (hatched bars) on the lower surface of the muscle cells in 1- to 7-day cultures. Data for days 5 and 7 were obtained from cultures prepared from stage 14 to 16 embryos. Data for other ages were obtained from cultures prepared from stage 22 to 24 embryos. The results are based on observations in one to three cultures at each age.

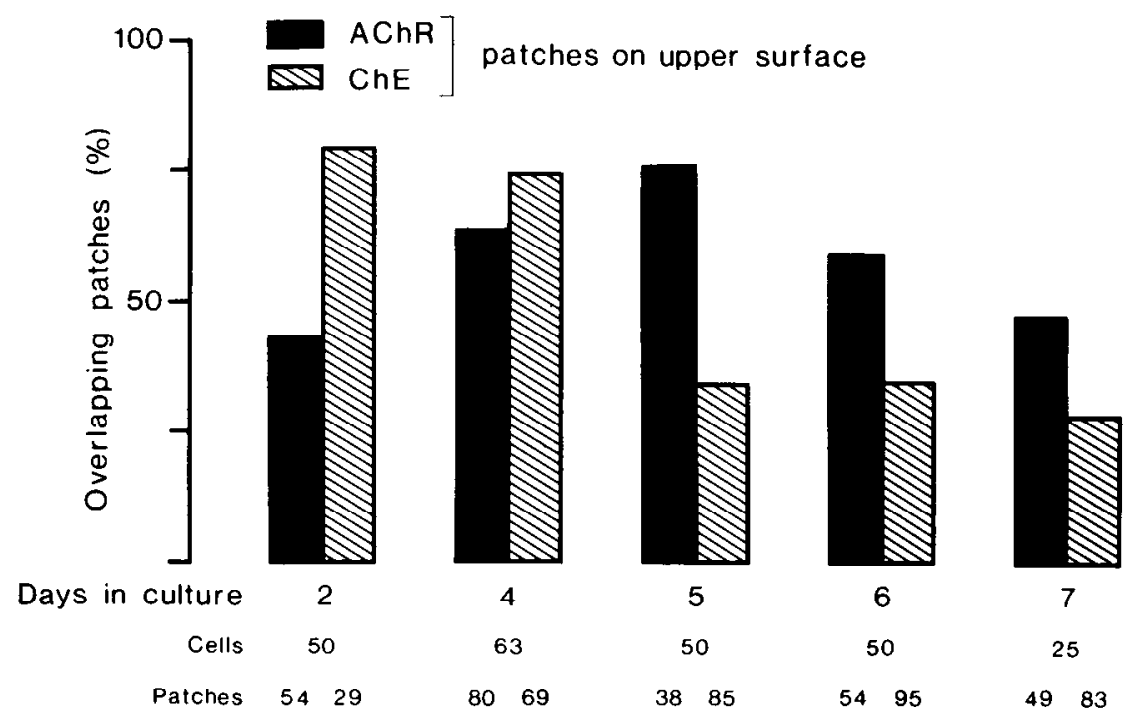

Figure 5. The percentage of $\mathrm{AChR}$ patches with $\mathrm{ChE}$ reaction product (solid bars) and the percentage of ChE patches with AChR stain (hatched bars) on the upper surface of the muscle cells in 2- to 7-day cultures. These data were collected from the same cells examined in Figure 4.

and (2) the incidence of AChR localization at sites of ChE activity was probably higher than indicated in Figures 4 and 5 since, in those experiments, AChR patches were examined only after ChE histochemistry.

Table I summarizes the precision of overlap of AChR and ChE patches. In 2- to 7-day cultures, 29 to $59 \%$ of overlapping patches had identical boundaries, whereas in 1 -day cultures, the incidence of perfect overlap was $11 \%$. The remaining examples fell into different categories of imperfect overlap (Table I), but even in these cases, the boundaries of one type of patch never extended more than a few micrometers beyond the boundaries of the other type.
In a previous study, it was found that $\mathrm{AChR}$ patches in 2-day cultures occupy only about $3 \%$ of the surface area of the muscle cells (Anderson et al., 1977). Similar measurements were made in the present study both for AChR patches and for $\mathrm{ChE}$ patches on the lower surface of 17 cells ( 12 cells in a 4-day culture and 5 cells in a 6day culture). Altogether, $51 \mathrm{AChR}$ patches and $57 \mathrm{ChE}$ patches were observed. The AChR patches occupied 1.7 $\pm 0.1 \%$ of the lower cell surface and the ChE patches occupied $2.2 \pm 0.3 \%$. Despite the fact that the patches occupied such a small fraction of the surface area, there were 46 examples of overlap. Clearly such a high incidence of overlap cannot be explained on the basis of a 
random distribution of both types of patch. Instead, there must be a high degree of spatial linkage between the mechanism which localizes AChRs and that which localizes ChE.

Invaginations at receptor and cholinesterase patches. Electron microscopy has demonstrated that some ChE patches occur at sites where the surface membrane is invaginated (Weldon et al., 1981). Evidence for such invaginations was also obtained in the present study by examining the patches at high magnification. At some patches, the ChE reaction product and/or AChR stain

\section{TABLE I}

Precision of overlap of receptor and cholinesterase patches Included are all cases of overlap in Figures 4 and 5 as well as additional data from cells on which either all of the receptor patches or all of the cholinesterase patches, but not always all of both, were examined for the corresponding stain.

$\begin{array}{cccccc}\text { Age of } & \begin{array}{c}\text { Number of } \\ \text { Cases of } \\ \text { Overlap }\end{array} & \begin{array}{c}\text { Patches } \\ \text { Overlap } \\ \text { Perfectly }^{a}\end{array} & \begin{array}{c}\text { AChR Patch } \\ \text { Extends } \\ \text { beyond } \\ \text { ChE Patch }\end{array} & \begin{array}{c}\text { ChE Patch } \\ \text { Extends } \\ \text { beyond } \\ \text { AChR Patch }^{a}\end{array} & \begin{array}{c}\text { Patches } \\ \text { Pverlap }\end{array} \\ \text { Partially }^{a}\end{array}$

$$
\text { days }
$$

Lower surface

$\begin{array}{rrrrrr}1 & 65 & 11 & 69 & 2 & 18 \\ 2 & 165 & 39 & 28 & 27 & 6 \\ 4 & 293 & 42 & 17 & 37 & 4 \\ 5 & 177 & 54 & 16 & 24 & 6 \\ 6 & 378 & 43 & 17 & 37 & 3 \\ 7 & 124 & 49 & 10 & 40 & 1\end{array}$

\begin{tabular}{crrrrr}
\multicolumn{2}{l}{ Upper surface } & & & & \\
2 & 36 & 31 & 33 & 8 & 28 \\
4 & 73 & 29 & 29 & 27 & 15 \\
5 & 29 & 59 & 24 & 14 & 3 \\
6 & 106 & 37 & 24 & 32 & 7 \\
7 & 23 & 52 & 4 & 18 & 26 \\
\hline
\end{tabular}

"Values are expressed as a percentage of the total.
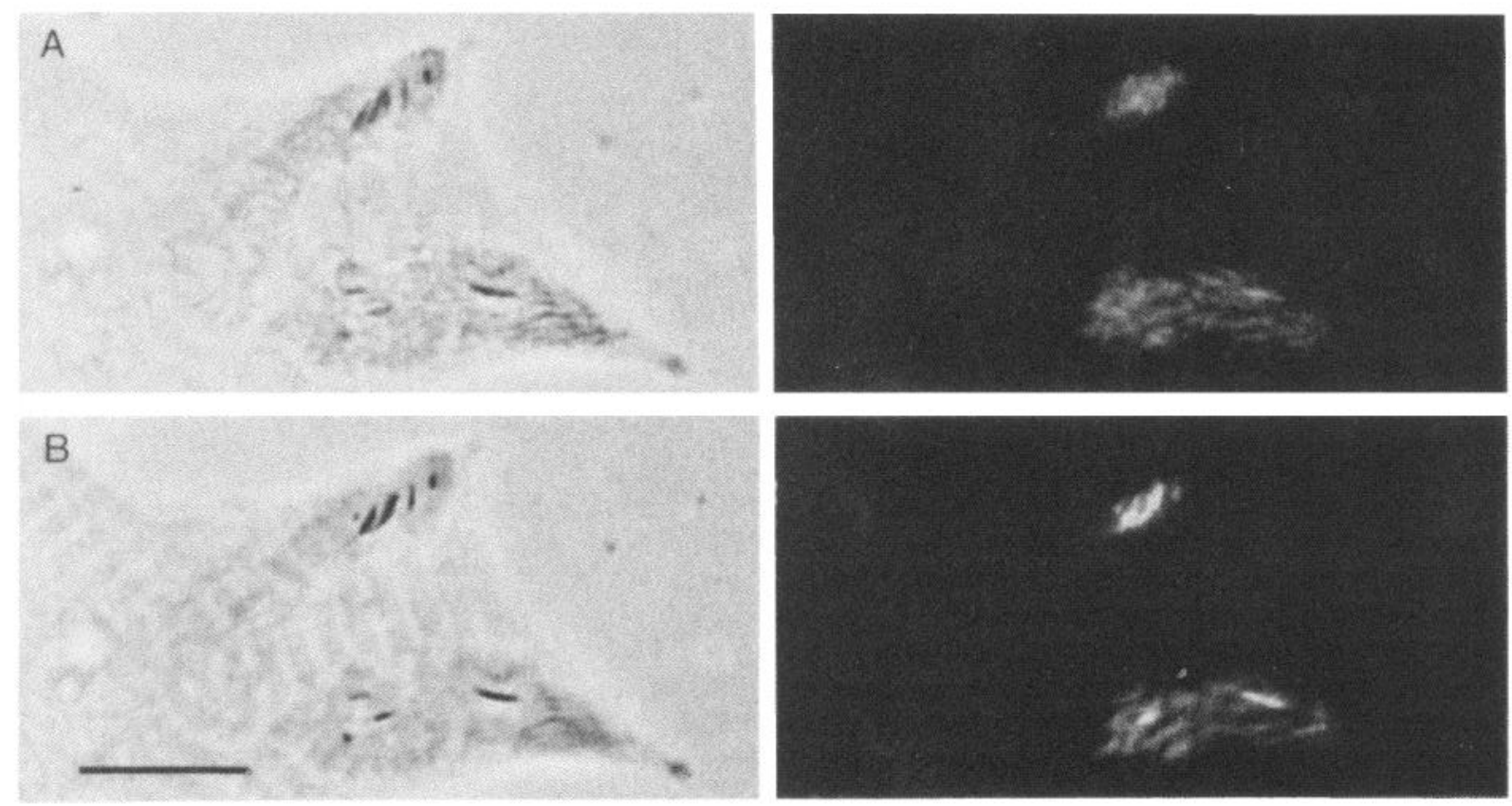

Figure 6. Invaginations at $\mathrm{ChE}$ (left) and AChR (right) patches. In $A$, the focus is on the lower surface of the cell and in $B$, the same field is seen with the plane of focus about $1 \mu \mathrm{m}$ into the cell. Note the invaginations revealed by both stains. Scale bar is 10 $\mu \mathrm{m}$. 
TABLE II

Receptor and cholinesterase patches in cultures grown without serum supplements

All cultures were 4 days old. "Standard" refers to glass chambers with a collagen-coated floor (see "Materials and Methods").

\begin{tabular}{|c|c|c|c|c|c|c|c|c|}
\hline \multirow[b]{2}{*}{ Culture Chamber } & \multirow[b]{2}{*}{ Cultures } & \multirow[b]{2}{*}{ Cells } & \multicolumn{3}{|c|}{ Upper Cell Surface } & \multicolumn{3}{|c|}{ Lower Cell Surface } \\
\hline & & & $\begin{array}{c}\text { AChR } \\
\text { Patches }\end{array}$ & $\begin{array}{c}\text { ChE } \\
\text { Patches }\end{array}$ & Overlap & $\begin{array}{c}\text { AChR } \\
\text { Patches }\end{array}$ & $\begin{array}{c}\text { ChE } \\
\text { Patches }\end{array}$ & Overlap \\
\hline & & & \multicolumn{3}{|c|}{ No. of examples } & \multicolumn{3}{|c|}{ No. of examples } \\
\hline Standard & 4 & 69 & 11 & 7 & 5 & 35 & 107 & 33 \\
\hline Untreated Falcon dish & 1 & 18 & 0 & 1 & 0 & 12 & 21 & 11 \\
\hline
\end{tabular}

tures. This suggests that the $\mathrm{ChE}$ was derived from the muscle cells but does not exclude the alternative possibility that the serum supplements in our culture medium contained ChE which became bound to the muscle cells. In order to evaluate these possibilities, two additional experiments were done. In one experiment, muscle cells were grown from the start in a culture medium containing only L-15 $(67 \%)$ without any serum supplements at all. After 4 days in culture, the muscle cells were much smaller than usual and even smaller than muscle cells in 1-day cultures grown under our standard conditions. Nevertheless, small AChR patches were observed, and more than $90 \%$ of those on the lower surface were also sites of ChE activity (Table II). This was the case even for a culture which was grown in an untreated $35-\mathrm{mm}$ Falcon dish rather than in our standard collagen-coated, glass culture chambers (Fig. $1 D$, Table II). In cultures grown without serum supplements, as in our standard cultures, the ChE patches on the lower surface outnumbered the AChR patches and 30 to $50 \%$ of them were also sites of high receptor density (Table II). A few ChE and AChR patches were also observed on the upper cell surface. These results indicate that the $\mathrm{ChE}$ was derived from the muscle cells.

A further indication that the ChE was of muscle cell origin was obtained under standard culture conditions by examining the inhibition of $\mathrm{ChE}$ activity at different concentrations of neostigmine. We knew from previous studies that much higher concentrations of anticholinesterases, such as neostigmine, are required for the inhibition of ChE in normal Xenopus muscle (Kullberg, 1974; Kullberg et al., 1980) than for the inhibition of ChE in mammalian serum (Burgen and Hobbiger, 1951; Foldes et al., 1958). We therefore determined the concentrations of neostigmine needed to inhibit the enzyme activity at AChR patches in our cultures. The results are summarized in Figure 7. The occurrence of $\mathrm{ChE}$ reaction product at $\mathrm{AChR}$ patches was partially reduced at a neostigmine concentration of $0.1 \mathrm{mg} / \mathrm{ml}$, the effect being more pronounced on the upper surface than on the lower surface. A much greater abolition of $\mathrm{ChE}$ reaction product was achieved at a concentration of $1 \mathrm{mg} / \mathrm{ml}$. Such high concentrations of neostigmine are also required for effective inhibition of ChE activity in normal Xenopus muscle (Kullberg et al., 1980).

Prior innervation is not required for the development of cholinesterase and receptor patches. In most of the experiments described above, the cultures were prepared from stage 22 to 24 embryos, shortly after nerve fibers begin to invade the myotomes (Kullberg et al., 1977). Therefore, even though nerve cells were not included in

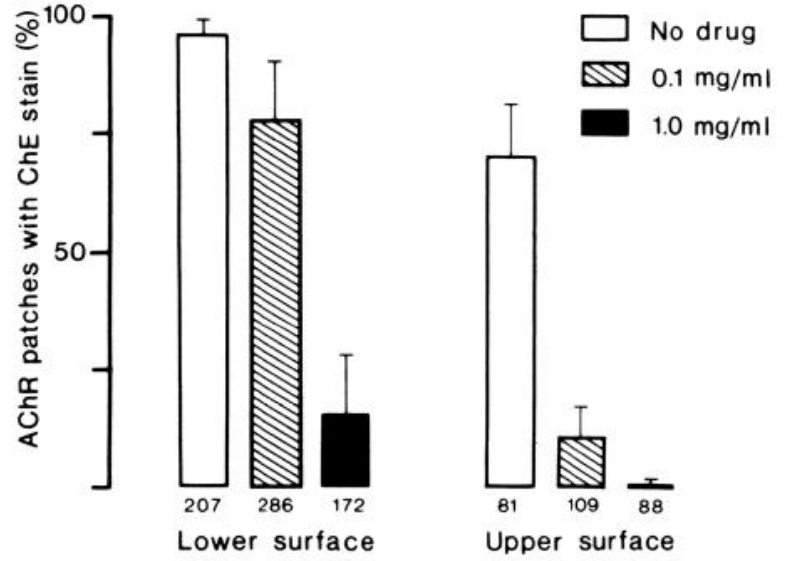

Figure 7. The percentage of $\mathrm{AChR}$ patches exhibiting $\mathrm{ChE}$ reaction product. The ChE histochemistry was done in the absence (open bars) or presence of neostigmine at concentrations of $0.1 \mathrm{mg} / \mathrm{ml}$ (hatched bars) and $1.0 \mathrm{mg} / \mathrm{ml}$ (solid bars). Each bar indicates the mean and standard error determined from 25 cells in each of three cultures ( 4 and 6 days old). The number of receptor patches examined is shown along the abscissa.

the cultures, it is possible that some of the muscle cells had been contacted by nerve prior to their removal from the embryo and that such prior contact is required for the development of the ChE patches (see Koenig and Vigny, 1978; Lomo and Slater, 1980). In order to eliminate this possible influence by the nerve, cultures were prepared from stage 14 to 16 embryos before there is any outgrowth of nerve fibers from the developing spinal cord (Kullberg et al., 1977; see also Hayes and Roberts, 1973). The cultures were examined for AChR and ChE patches after 5 and 7 days. The size, number, and incidence of overlap of both types of patch in these cultures (Fig. 1B; 5- and 7-day values in Figs. 4 and 5) were essentially similar to the corresponding findings obtained with our standard cultures, thereby indicating that the development of these patches does not require previous contact by nerve.

\section{Discussion}

The present study has revealed that many of the sites of high AChR density which develop on the surface of Xenopus myotomal muscle cells in culture are also sites of ChE activity. The ChE at these surface patches, like the AChRs, appears to be produced by the muscle cells. The surface patches develop in the absence of nerve, even if the muscle cells have never been innervated. 
Since they occupy a small fraction (less than $3 \%$ ) of the cell surface, it is clear that the localization of AChRs and ChE at these sites does not occur by chance. Rather, it is likely that the cellular mechanisms involved in the localization of these two molecules are spatially linked.

The linkage may not be absolute since not all AChR patches exhibited ChE activity and not all ChE patches exhibited AChR stain. Alternatively, it could be that the lack of $\mathrm{ChE}$ or $\mathrm{AChRs}$ at some surface patches is related to the rates at which both molecules are supplied to and leave those sites. For example, if the supply of $\mathrm{ChE}$ to developing surface patches lags behind the supply of AChRs, then newly formed patches would exhibit a high density of AChRs without corresponding ChE activity. This could account for the lower incidence of ChE activity at AChR patches in 1-day cultures than in older cultures (Fig. 4). In addition, receptor staining has revealed that some patches survive for the lifetime of the cell, whereas others do not (Moody-Corbett and Cohen, 1980). If the loss of AChRs precedes the loss of ChE from the latter patches, then this would result in ChE patches without a corresponding high density of AChRs.

Greater numbers of AChR and ChE patches, and examples of overlap, were observed on the lower surface than on the upper surface of the cells. Indeed in 1-day cultures, patches were rarely observed on the upper surface. These differences in the incidence of patches on the upper and lower surfaces may be due, at least in part, to technical limitations. The cultures were examined with the lower cell surface closest to the microscope objective. Accordingly, AChR and ChE patches on the upper surface were resolved less clearly, especially in thicker portions of the cells or in regions where the upper surface was sloping. Both types of patch can also be obscured by intracellular yolk granules which are especially numerous in 1-day cultures. In addition to these technical limitations, it may be that the development of AChR and ChE patches is facilitated at sites of contact with the culture dish (Moody-Corbett and Cohen, 1979; Bloch and Geiger, 1980). Nevertheless, it is clear that both types of patch also develop at sites which are not in contact with a solid substrate.

A high density of AChRs and localized ChE activity are characteristic features of the neuromuscular junction. Besides these features, the postsynaptic membrane in muscle exhibits the following ultrastructural specializations: the plasma membrane is more electron dense than nonsynaptic plasma membrane, it has filamentous material applied to its inner surface, and it has a basal lamina on its outer surface (Birks et al., 1960; Fertuck and Salpeter, 1974; Porter and Barnard, 1975). A similar combination of ultrastructural specializations is observed also at discrete sites on the surface of embryonic Xenopus muscle cells cultured without nerve (Weldon and Cohen, 1979). Moreover, these sites of ultrastructural specialization also exhibit ChE activity (Weldon et al., 1981). In view of the high incidence of $\mathrm{ChE}$ activity at AChR patches, it seems likely that many, if not all, of the AChR patches are in fact located at the sites of ultrastructural specialization. In all of these respects then, there appears to be very close similarity between $\mathrm{AChR}$-ChE patches in culture and postsynaptic membrane.
One difference concerns their surface geometry. The Xenopus myotomal neuromuscular junction has very shallow junctional folds, only a fraction of a micrometer deep (Kullberg et al., 1977), whereas some of the AChR$\mathrm{ChE}$ patches in culture had invaginations of more than $1 \mu \mathrm{m}$. In addition, electron microscopy has indicated that some of the deep invaginations at ChE patches are similar to those at the myotendinous junction in vivo. Although the myotendinous junction, in Xenopus myotomal muscle and in other muscles, is a site of ChE activity (Couteaux, 1963; Filogamo and Gabella, 1967; Cohen, 1980), its invaginations do not normally exhibit a high AChR density (Anderson and Cohen, 1974; Cohen, 1980). Thus, deep invaginations with a high density of AChRs may be a unique feature which develops only in culture. In any event, invaginations were seen at only some patches in culture. The occurrence of AChR-ChE patches without any obvious invaginations, and of non-invaginated sites exhibiting postsynaptic ultrastructure and ChE activity (Weldon et al., 1981), is indicative that embryonic Xenopus muscle cells in culture generate postsynaptic-like sites in the absence of nerve.

Discrete sites of high AChR density on embryonic muscle cells cultured without nerve are common in cultures derived from chick (Vogel et al., 1972; Fischbach and Cohen, 1973), rat (Axelrod et al., 1976), and mouse (Powell and Friedman, 1977). It has also been found, at least for the chick cultures, that such patches develop even if the cells are derived from developing muscle which has never been innervated (Bekoff and Betz, 1976). In these respects then, the differentiation of other embryonic muscle cells in culture is similar to that seen in cultures of embryonic Xenopus muscle cells. However, in contrast to our findings on Xenopus cultures, ChE activity has rarely been observed either in association with AChR patches or at other discrete surface sites on noninnervated, cultured muscle cells derived from rat (Axelrod et al., 1978; Koenig and Vigny, 1978) or chick (Rubin et al., 1979). The reason for this difference between Xenopus muscle cultures and other muscle cultures is not clear and factors such as differences in culture conditions cannot be excluded at present. Another consideration arises from studies which indicate that muscle electrical or contractile activity is important for the localization of $\mathrm{ChE}$ at rat and chick neuromuscular junctions (Koenig and Vigny, 1979; Rubin et al., 1979, 1980; Weinberg and Hall, 1979; Lomo and Slater, 1980). It may be therefore that, in the absence of innervation, cultured rat and chick muscle cells do not contract sufficiently to permit ChE localization on their surface. On the other hand, muscle electrical or contractile activity is clearly not required for the localization of ChE on the surface of non-innervated Xenopus muscle cells in culture because these cells do not exhibit such activity (Harrison, 1910; Anderson et al., 1977, 1979). In this vein, it is also noteworthy that muscle activity appears less important in the control of other muscle properties in amphibians than in rat and chick (Antony and Tonge, 1980).

In adult muscle, the denervated neuromuscular junction is a preferred site of reinnervation (Miledi, 1960; Letinsky et al., 1976; Sanes et al., 1978). In view of their similarity to postsynaptic membrane, the question there- 
fore arises whether AChR-ChE patches are also preferred sites of innervation. Although this possibility has not been excluded, previous studies on mixed spinal cord (SC) and muscle cultures derived from Xenopus embryos (Anderson et al., 1977; Anderson and Cohen, 1977) and chick embryos (Frank and Fischbach, 1979) have revealed that innervation can occur at sites which do not initially have a high receptor density. These studies also have indicated that innervation may actually cause the disappearance of AChR patches initially present elsewhere on the cell. Indeed, in the Xenopus cultures, the SC-contacted muscle cells often have a high AChR density at sites of contact and the majority of those cells do not have any of the characteristic AChR patches that are virtually always present on muscle cells not contacted by SC neurites (Anderson et al., 1977; Cohen and Weldon, 1980). The distribution of ChE on SC-contacted muscle cells is similar to that of the AChRs (F. Moody-Corbett and M. W. Cohen, manuscript in preparation). At present then, it is not clear whether the AChR-ChE patches that develop on non-innervated muscle cells subserve any function. Rather, these patches may simply reflect intrinsic muscle mechanisms whose operation is linked to the differentiation of the cells and subject to external regulating influences such as innervation.

\section{References}

Aitken, J. T. (1950) Growth of nerve implants in voluntary muscle. J. Anat. 84: 38-49.

Anderson, M. J., and M. W. Cohen (1974) Fluorescent staining of acetylcholine receptors in vertebrate skeletal muscle. J. Physiol. (Lond.) 237: 385-400.

Anderson, M. J., and M. W. Cohen (1977) Nerve-induced and spontaneous redistribution of acetylcholine receptors on cultured muscle cells. J. Physiol. (Lond.) 268: 757-773.

Anderson, M. J., M. W. Cohen, and E. Zorychta (1977) Effects of innervation on the distribution of acetylcholine receptors on cultured muscle cells. J. Physiol. (Lond.) 268: 731-756.

Anderson, M. J., Y. Kidokoro, and R. Gruener (1979) Correlation between acetylcholine receptor localization and spontaneous synaptic potentials in cultures of nerve and muscle. Brain Res. 166: 185-190.

Antony, M. T., and D. A. Tonge (1980) Effects of denervation and botulinum toxin on muscle sensitivity to acetylcholine and acceptance of foreign innervation in the frog. J. Physiol. (Lond.) 303: 23-32.

Axelrod, D., P. Ravdin, D. E. Koppel, J. Schlessinger, W. W. Webb, E. L. Elson, and T. R. Podleski (1976) Lateral motion of fluorescently labelled acetylcholine receptors in membranes of developing muscle cells. Proc. Natl. Acad. Sci. U. S. A. 73: 4594-4598.

Axelrod, D., P. M. Ravdin, and T. R. Podleski (1978) Control of acetylcholine receptor mobility and distribution in cultured muscle membranes. Biochim. Biophys. Acta 511: 23-38.

Bekoff, A., and W. H. Betz (1976) Acetylcholine hotspots: Development on myotubes cultured from aneural limb buds. Science 193: 915-917.

Bennett, M. R., and A. G. Pettigrew (1974) The formation of svnapses in striated muscle during development. J. Physiol. (Lond.) 241: 515-545.

Bevan, S., and J. H. Steinbach (1977) The distribution of $\alpha$ bungarotoxin binding sites on mammalian skeletal muscle developing in vivo. J. Physiol. (Lond.) 267: 195-213.

Birks, R. I., H. E. Huxley, and B. Katz (1960) The fine structure of the neuromuscular junction of the frog. J. Physiol. (Lond.) 150: 134-144.
Bloch, R. J., and B. Geiger (1980) The localization of acetylcholine receptor clusters in areas of cell-substrate contact in cultures of rat myotubes. Cell 21: 25-35.

Burgen, A. S. V., and F. Hobbiger (1951) The inhibition of cholinesterases by alkyl phosphates and alkylphenol phosphates. Br. J. Pharmacol. 6: 593-605.

Chow, I. (1980) Distribution of acetylcholine receptors in the myotomes of Xenopus laevis during normal development. Ph.D. thesis, McGill University, Montreal.

Cohen, M. W. (1980) Development of an amphibian neuromuscular junction in vivo and in culture. J. Exp. Biol. 89: 43-56.

Cohen, M. W., and P. R. Weldon (1980) Localization of acetylcholine receptors and synaptic ultrastructure at nerve-muscle contacts in culture: Dependence on nerve type. J. Cell Biol 86: 388-401.

Couteaux, R. (1963) The differentiation of synaptic areas. Proc. R. Soc. Lond. (Biol.) 158: 457-480.

Diamond, J., and R. Miledi (1962) A study of foetal and newborn rat muscle fibres. J. Physiol. (Lond.) 162: 393-408.

Fertuck, H. C., and M. M. Salpeter (1974) Localization of acetylcholine receptor by ${ }^{125} \mathrm{I}-\alpha$-bungarotoxin binding at mouse motor endplates. Proc. Natl. Acad. Sci. U. S. A. 71 : 1376-1378.

Fex, S., B. Sonesson, S. Thesleff, and J. Zelena (1966) Nerve implants in botulinum poisoned mammalian muscle. J. Physiol. (Lond.) 184: 872-882.

Filogamo, G., and G. Gabella (1967) The development of neuromuscular correlations in vertebrates. Arch. Biol. (Liege) 78 . 9-60.

Fischbach, G. D., and S. A. Cohen (1973) The distribution of acetylcholine sensitivity over uninnervated and innervated muscle fibers grown in cell culture. Dev. Biol. 31: 147-162.

Foldes, F. F., G. Van Hees, D. L. Davis, and S. P. Shanor (1958) The structure-action relationship of urethane type cholinesterase inhibitors. J. Pharmacol. Exp. Ther. 122: 457-464.

Frank, E., and G. D. Fischbach (1979) Early events in neuromuscular junction formation in vitro. Induction of acetylcholine receptor clusters in the postsynaptic membrane and morphology of newly formed synapses. J. Cell Biol. 83: 143158.

Hamilton, L. (1969) The formation of somites in Xenopus. J. Embryol. Exp. Morphol. 22: 253-264.

Harrison, R. G. (1910) The outgrowth of the nerve fibre as a mode of protoplasmic movement. J. Exp. Zool. 9: 787-846.

Hayes, B. P., and A. Roberts (1973) Synaptic junction development in the spinal cord of an amphibian embryo: An electron microscope study. Z. Zellforsch. Mikrosk. Anat. 79: 198-208.

Karnovsky, M. J. (1964) The localization of cholinesterase activity in rat cardiac muscle by electron microscopy. J. Cell Biol. 23: 217-232.

Koenig, J., and M. Vigny (1978) Neural induction of the $16 \mathrm{~S}$ acetylcholinesterase in muscle cell cultures. Nature 271:7577.

Koenig, J., and M. Vigny (1979) Influence of neurons and contractile activity on acetylcholinesterase and acetylcholine receptors in muscle cell cultures. Prog. Brain Res. 49: 484.

Kullberg, R. W. (1974) Onset and development of synaptic activity at an amphibian neuromuscular junction. Ph.D. thesis, McGill University, Montreal.

Kullberg, R. W., T. L. Lentz, and M. W. Cohen (1977) Development of the myotomal neuromuscular junction in Xenopus laevis: An electrophysiological and fine-structural study. Dev. Biol. 60: 101-120.

Kullberg, R. W., F. S. Mikelberg, and M. W. Cohen (1980) Contribution of cholinesterase to developmental decreases in the time course of synaptic potentials at an amphibian neuromuscular junction. Dev. Biol. 75: 255-267. 
Letinsky, M. S., K. H. Fischbeck, and U. J. McMahan (1976) Precision of reinnervation of original postsynaptic sites in frog muscle after a nerve crush. J. Neurocytol. 5: 691-718.

Lomo, T., and C. R. Slater (1980) Control of junctional acetylcholinesterase by neural and muscular influence in the rat. $\mathrm{J}$. Physiol. (Lond.) 303: 191-202.

Miledi, R. (1960) Properties of regenerating neuromuscular synapses in the frog. J. Physiol. (Iond.) 154: 190-205.

Miledi, R. (1962) Induced innervation of end-plate free muscle segments. Nature 193: 281-282.

Moody-Corbett, F., and M. W. Cohen (1979) Development of synaptic specializations on cultured non-innervated muscle cells at sites of contact with the culture dish. Soc. Neurosci. Abstr. 5: 486.

Moody-Corbett, F., and M. W. Cohen (1980) Stability of ACh receptor patches on cultured muscle cells. Can. Fed. Biol. Soc. Proc. 23: 162.

Nieuwkoop, P. D., and J. Faber (1967) Normal Table of Xenopus laevis (Daudin), Ed. 2, North-Holland, Amsterdam.

Porter, C. W., and E. A. Barnard (1975) The density of cholinergic receptors at the endplate postsynaptic membrane: Ultrastructural studies in two mammalian species. J. Membr. Biol. 20: 31-49.

Powell, J. A., and B. A. Friedman (1977) Electrical membrane activity: Effect on distribution, incorporation and degradation of acetylcholine receptors in the membranes of cultured muscle. J. Cell Biol. 75: 321a.

Rubin, L. L., S. M. Schuetze, and G. D. Fischbach (1979) Accumulation of acetylcholinesterase at newly formed nervemuscle synapses. Dev. Biol. 69: 46-58.

Rubin, L. L., S. M. Schuetze, C. L. Weill, and G. D. Fischbach (1980) Regulation of acetylcholinesterase appearance at neuromuscular junctions in vitro. Nature 283: 264-267.

Sanes, J. R., L. M. Marshall, and U. J. McMahan (1978) Reinnervation of muscle fiber basal lamina after removal of myofibers. J. Cell Biol. 78: 176-198.

Vogel, Z., A. J. Sytkowski, and M. W. Nirenberg (1972) Acetylcholine receptors of muscle grown in vitro. Proc. Natl. Acad. Sci. U. S. A. 60: 3180-3184.

Weinberg, C. B., and Z. W. Hall (1979) Junctional form of acetylcholinesterase restored at nerve-free endplates. Dev. Biol. 68: 631-635.

Weldon, P. R., and M. W. Cohen (1979) Development of synaptic ultrastructure at neuromuscular contacts in an amphibian cell culture system. J. Neurocytol. 8: 239-259.

Weldon, P. R., F. Moody-Corbett, and M. W. Cohen (1981) Ultrastructure of sites of cholinesterase activity on amphibian embryonic muscle cells cultured without nerve. Dev. Biol., in press. 